\title{
EL HONOR A LOS MÁRTIRES CRISTIANOS EN ANTIOQUÍA Y CONSTANTINOPLA EN LOS SIGLOS IV Y V SEGÚN SAN JUAN CRISÓSTOMO
}

\author{
Spyros P. Panagopoulos \\ Investigador independiente. Patras, Grecia
}

Resumen: Este artículo trata sobre el honor de los mártires cristianos durante los primeros siglos del cristianismo. En particular, se hará referencia a la posición que ocupa el honor a los mártires en el pensamiento y la obra de San Juan Crisóstomo, uno de los más grandes padres del cristianismo. La mayor parte del artículo se centrará en el análisis de los sermones y escritos de Juan Crisóstomo, relacionados con la vida de los mártires. Finalmente, este artículo explorará una serie de roles que los mártires, a través del culto emergente de la Iglesia, han cumplido para los cristianos a fines del siglo $\mathrm{V}$.

Palabras clave: Juan Crisóstomo - mártires cristianos - martirio - cristianismo oriental - Constantinopla.

\section{THE HONOR TO THE CHRISTIAN MARTYRS IN ANTIOCH AND CONSTANTINOPLE IN THE 4TH AND 5TH CENTURIES ACCORDING TO SAINT JOHN CHRYSOSTOM}

\begin{abstract}
This paper deals with the honor to Christian martyrs during the first centuries of Christianity. In particular, reference will be made to the position held by the honor to martyrs in the thought and work of St. John Chrysostom, one of the greatest fathers of Christianity. A great part will focus on the analysis of sermons and writings by John Chrysostom, related to the martyrs' life. Finally, this paper will explore a series of roles that martyrs, through the emerging worship of the Church, have fulfilled for Christians at the end of the fifth century.
\end{abstract}

Keywords: John Chrysostom - Christian martyrs - martyrdom - Oriental Christianity - Constantinople.

\section{Recibido: 23.12.2019 - Aceptado: 31.05.2020}

Correspondencia: Spyros P. Panagopoulos.

Correo: spyrpan1@gmail.com

Licenciado en filología griega y en filosofía en la Universidad de Patras (Grecia). Investigador de la filología e historia bizantinas y estudios patrísticos 


\section{Introducción}

Tuan Crisóstomo (347-407 d.C.) fue probablemente el predicador más prominente de la Iglesia Ortodoxa Griega y su obra es una fuente de información sobre el tema del honor de los mártires a fines del siglo IV. Él fue uno de los más grandes jerarcas de la Iglesia Ortodoxa y recibió muchos y diversos dones de Dios, y como siervo bueno y fiel de Dios cultivó los talentos que le fueron dados, ${ }^{1}$ como también se registra en el Apolytikion de su fiesta. Por su formación intelectual y su origen, es el único de los grandes Padres orientales que procede de la Escuela de Antioquía. ${ }^{2}$ Crisóstomo inspiró a muchas generaciones de cristianos, de todas las clases sociales. Sus textos se han salvado, y los fieles, tanto el clero como la gente, tanto los solteros como los casados, los han envidiado. A través de su obra, se revela el maestro inspirado y el líder de la auténtica vida cristiana.

Desde la época de Crisóstomo, la Iglesia de Antioquía atribuía honor a muchos mártires locales. ${ }^{3}$ La mayoría de ellos fueron enterrados en un cementerio fuera de las murallas de la ciudad, en ruta a Daphne (el barrio noble de Antioquía), porque las leyes del Estado prohibían el entierro dentro de los límites de la ciudad. ${ }^{4}$ Incluso las reliquias de San Ignacio fueron enterradas cerca de su antigua sede del obispado, mientras que su recuperación de Roma a Antioquía se llevó a cabo durante el período de la estancia de Crisóstomo en la última ciudad. ${ }^{5}$

$1 \quad$ Elena Martin, “Golden Mouths and Speaking Bodies: John Chrysostom's Depiction of Christian Martyrs", Issue 8 (2006): 1-20.

2 J. Maxwell, Christianization and communication in late antiquity, Cambridge, Cambridge University Press, 2009

3 Stephens Saint John Chrysostom, 124.

4 Sobre las prácticas de enterramiento en el mundo antiguo véase indicativamente, F. Retief, \& Louise Cilliers, "Burial Customs, the Afterlife and the Pollution of Death in Ancient Greece", Acta Theologica Supplementum 7(2005): 44-61.

5 Crisóstomo, In S. Ignatium martyrem, 5, PG 50, col. 594 y G. Downey, Ancient Antioch, Princeton, 1963, 293, citando Jerónimo, De viris illustribus, 16 y Stephens, Saint John Chrysostom, 125. Wendy Mayer, The Cult of the Saints: Select Homilies and Letters, Crestwood, 2006, 101 señala que en el siglo quinto, la reliquia de San Ignacio fue nuevamente transferida a las murallas de la ciudad en una iglesia construida con el propósito de su refugio. 
La educación filosófica fue un medio importante para desarrollar las ideas y creencias de Crisóstomo en contra de sus posturas teológicas, su pensamiento intelectual y su retórica de habilidad. Profundamente arraigada en ella, la educación filosófica clásica formó como un punto sus posiciones teológicas. Esto es particularmente evidente en su habilidad verbal, la estructura y el contenido de sus conceptos sermónicos, así como en la forma sermónica en que comunicó sus mensajes teológicos a su rebaño. Al estudiar la obra de Crisóstomo, lo que se menciona en el honor al mártir no podemos separarlo de sus experiencias y su tiempo : las palabras que usa, el orden en que las coloca, los contrastes, las comparaciones y las metáforas que utiliza reflejan claramente su educación helenística y clásica. ${ }^{6}$ La educación retórica clásica de Crisóstomo es evidente en sus homilías de mártires, que fueron declamadas el día de la memoria de los mártires. Estas homilías reflejan la tradición profundamente martirizada de la iglesia local, pero al mismo tiempo también traicionan el comienzo de la cristianización del imperio entero. ${ }^{7}$ Así, el grupo de estos sermones se convirtió en una herramienta valiosa para la consolidación y la difusión del honor a los mártires de la iglesia local.

En el 397 d.C., sin embargo, la actividad homilética de Crisóstomo se desarrolló cuando de repente él fue elegido Patriarca de Constantinopla. Es interesante que después su elección al Arzobispado de Constantinopla y durante su visita a uno de los lugares de peregrinación locales, los emisarios del Emperador lo sacaron de Antioquía para que lo llevaran y lo entronizaran en Constantinopla. En esos tiempos, Constantinopla, aunque se desarrollaba politicamente como capital de Bizancio, no tenía la tradición espiritual y religiosa de Antioquía. Con su prestigio político llegó a Constantinopla al mismo tiempo la nueva influencia religiosa y espiritual del cristianismo. Desde su fundación, los edificios de los nuevos

$6 \quad$ Kelly. Golden Mouth, 7.

7 Stephens Saint John Chrysostom, 125. En Antioquía, el culto a la adoración de los mártires era una herramienta para combatir la tradicional religión politeísta griega y para la diversificación de los cristianos por parte de los judíos que tenían su propio culto popular en Antioquía, dedicado a la adoración de los mártires macabeos. Por la compleja relación entre los judíos de Antioquía y los cristianos en el siglo IV véase, Wayne A. Meeks, Jews and Christians in Antioch in the First Four Centuries of the Common Era, Missoula, 1978. 
templos y otros sitios religiosos, que fueron reconstruidos, debían formar parte integrante de la vida cívica e intelectual de los ciudadanos. Cuando Crisóstomo se convirtió en Arzobispo de Constantinopla, la ciudad todavía estaba en desventaja con respecto a Antioquía, debido a la falta y ausencia de mártires locales.

\section{La presencia histórica de las reliquias y el honor a los mártires en Constantinopla hasta la época de Juan Crisóstomo}

Está probado que el surgimiento de Constantinopla como centro del honor de las diversas reliquias de la Pasión de Cristo tuvo sus raíces en la edad de la fundación de la ciudad bajo el reino de Constantino el Grande. ${ }^{8}$ Según las fuentes, el propio Constantino el Grande tomó parte de la pieza de la Vera Cruz y los clavos sagrados por su madre Santa Elena, que, según la tradición, las descubrió durante su peregrinación en Jerusalén. ${ }^{9}$ Mientras la credibilidad histórica de las diversas narrativas ha sido cuestionada por muchos investigadores, ${ }^{10}$ las fuentes históricas ciertamente revelan una necesidad temprana de vincular el honor de los restos más notables del cristianismo con Constantino el Grande, su familia y la nueva capital de Bizancio. ${ }^{11}$

8 Por esta tradición véase Patria Konstantinoupoleos, II 20, en: Theodore Preger, Scriptores Originum Constantinopolitanarum, II, Bibliotheca scriptorum Graecorum et Romanorum Teubneriana, Lipsia, 1907, 1613-1619, 1741-1746 y $3312-3321$.

9 Sophia Mergiali-Sahas, "Byzantine Emperors and Holy Relics. Use, and Misuse of Sanctity and Authority", Jahrbuch der Österreichischen Byzantinistik, 51(2001): 41-60, aquí en 42.

10 Por esta evidencia contradictoria véase Frances M. Young, "Jesus Christ, foundation of Christianity", en Margaret M. Mitchel, The Cambrige History of Christianity, vol. 1, Cambridge, 2008, 1-36.

11 U. Koenen, "Symbol und Zierde auf dem Diadem und Kronreif spätantiker und byzantinischer Herrscher und die Kreuzauffindungslegende bei Ambrosius", Jahrbuch für Antike und Christentum 39(1996): 170-199, aquí en 175. La sugerencia de Koenen de que Ambrose conecta las relíquias con Constantino el Grande para distraer las dudas sobre su autenticidad parece faltar, ya que ignora el poder legítimo inherente en el supuesto uso por Constantino de los elementos y piezas, y especialmente de los santos clavos, como una prueba tangible del mandato divino del Emperador. 
Una motivación similar es citada por Paulino de Nola sobre el presunto recuerdo de los restos de las reliquias de los santos Andrés el Apóstol y Timoteo a la Basileuousa polis en 336 d.C. por Constantino el Grande. ${ }^{12}$ Como señala Mango, la creencia cristiana de que las reliquias de los mártires son una protección más fuerte que las murallas y los torres de la ciudad ya se refleja en los escritos de Crisóstomo, ${ }^{13}$ cuyos sermones sobre los mártires egipcios y el mártir Focas de Sinope proporcionan pruebas suficientes, unos treinta años antes de los escritos de Paulino. ${ }^{14}$

Si la implicación de Constantino y Elena en la recuperación de reliquias en Constantinopla sigue siendo controvertida y difícil de justificar, no cabe duda de que los emperadores desde Constancio II y más allá desempeñaron un papel activo en la adquisición de reliquias sagradas de los mártires y su recuperación en la Basileuousa polis ${ }^{15}$, así como las reliquias de los apóstoles Andrés y Lucas el Evangelista desde Grecia el siguiente año, las cuales fueron depositadas bajo el altar del recién construido templo de los Santos Apóstoles. ${ }^{16}$ Menos confiado en la participación de Constantino el Grande sobre la recuperación de reliquias de los tres «apóstoles» en la Basileuousa polis, es su papel en el traslado de las reliquias de los mártires palestinos, Pánfilo, Teodulo con sus compañeros, desde Antioquía a Constantinopla en 360 d.C., como se hace referencia en fuentes posteriores. Estas fuentes implican que las reliquias

12 Paulino de Nola, Carmen 19. 137 ff. Según Jerónimo y otras fuentes históricas confiables, la recuperación de los cuerpos de los santos Timoteo, Andrés y Lucas ocurrió en 356/357 d.C., es decir, durante el reinado de Constantino el Grande. Varias revisiones del Cronicón pascual, sin embargo, apoyan la fecha de 336 d.C. Véase C. Mango, "Constantine's Mausoleum and the Translation of Relics”, Byzantinische Zeitschrift 83(1990): 51-62.

13 Mango, "Constantine's Mausoleum", 59.

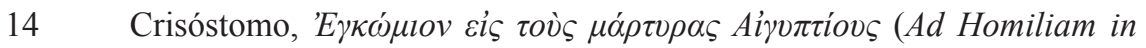

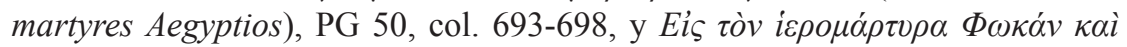

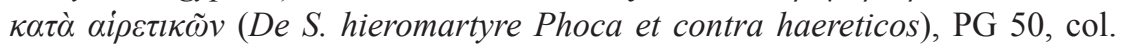
699-706.

15 Por las razones por las que Constantino el Grande fue persuadido para realizar la recuperación de reliquias de los santos Timoteo, Andrés y Lucas en Constantinopla, véase Mango, "Constantine's Mausoleum”, 59-60.

16 Cronicón pascual 542, 14-18, en Michael \& Mary Whitby, Chronicon Paschale 284-628 AD, Liverpool University Press, 1989, 52. 
"enteras e intactas" de estos santos se depositaron en medio ( $\kappa v ́ \kappa \lambda \iota v v)$ de la Gran Iglesia (Santa Sofía) antes de su inauguración, y que a partir de entonces se mencionaron en el 16 de febrero. ${ }^{17}$

Durante el reino de Arcadio (395-408 d.C.), el interés imperial en las reliquias de los santos parece ser más intenso. Hacia el final del año 398 d.C., la emperatriz Elia Eudoxia ordenó el traslado de los restos de algunos mártires anónimos desde Constantinpola al templo de Tomás el Apóstol en Dripia, un lugar a casi 25 kilómetros al oeste de la ciudad, hacia el mar. ${ }^{18}$ Como aprendemos de los dos sermones declamados por Crisóstomo, en este caso la ceremonia de la recuperación de reliquias comenzó en la iglesia de Santa Sofía a medianoche. A pesar de la larga distancia, la emperatriz y otros miembros distinguidos de la corte imperial participaron en la procesión y acompañaron las reliquias de estos mártires durante todo el viaje hasta a Dripia. ${ }^{19} \mathrm{Al}$ día siguiente, el emperador Arcadio y su séquito también visitaron este lugar de peregrinación y rindieron homenaje a los mártires. ${ }^{20}$ Como sugiere Maraval, sigue siendo incierto si otros miembros

17 Véase "Georgii Cedreni Historiarum Compendium" en I. Bekker, Corpus Scriptorum Historiae Byzantinae I, 1838, 5237-5239, "Synaxarium Ecclesiae Constantinopolitanae" en Delehaye, H., Synaxarium Ecclesiae Constantinopolitanae, Société de Bollandistes, Bruxelles, 1902, col. 4675346755. Pierre Maraval, Lieux saints et pelerinages d'Orient. Histoire et géographie. Des origines à la conquête arabe, París, 1985, 93; J. Ebersolt, Sanctuaires de Byzance. Recherches sur les anciens trésors des églises de Constantinople, París, 1921, 5-6.

18 Por el edificio y la ubicación de la iglesia véase, R. Janin, Constantinople Byzantine. Développement urbain et répertoire topographique, París, 1964, 445; Janin, “ La géographie ecclésiastique”, 251-252; G. Dagron, Naissance d'une capitale. Constantinople et ses institutions de 330 à 451, París, 1984, 102, y Maraval, Lieux saints et pelerinages d'Orient, 94.

19 La procesión llegó a Dripia antes del amanecer. Esta vez, Crisóstomo, declamó su primea homilía, lleno de elogios por la emperatriz y su entusiasmo religioso. Véase, Crisóstomo, Homilia dicta postquam reliquiae martyrum, Homilía B, PG 63, col. 468-472.

20 Después de la partida de Arcadio, el Patriarca declamó una segunda

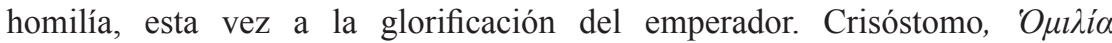

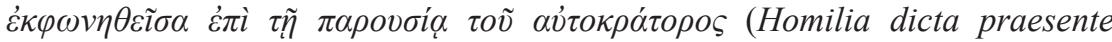
imperatore), PG 63, col. 473-478. 
de la familia imperial, en particular la hija de Arcadio, estaban en el proceso de recuperar estos restos. La fundación del templo sagrado de San Andrés por la hija de Arcadio no implica necesariamente su presencia en la llegada de los nuevos restos en la Baslileuousa polis. ${ }^{21}$

El 19 de mayo de 406 d.C., se dice que Arcadio ordenó la recuperación de reliquias del profeta Samuel desde Palestina hasta Constantinopla. ${ }^{22}$ Según el Cronicón pascual, el cuerpo del profeta llegó a Constantinopla:

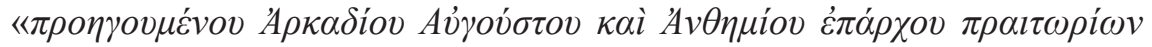

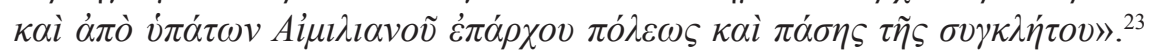
Pero antes de la llegada de la reliquia sagrada del profeta a la ciudad, estos restos habían atraído "jungerentur populorum examina"24, quien lo recibió y lo honró en el transcurso de la recuperación desde Palestina hasta Calcedón. Cuando las reliquias del profeta finalmente llegaron al muelle de Calcedón, ${ }^{25}$ fueron trasladadas al templo de Santa Sofía, donde "fueron situadas allí por un tiempo determinado". ${ }^{26}$ Unos años más tarde, el 5 de

21 Véase, Cronicón pascual, 566, 14-15, Whitby, Chronicon Paschale, 53.

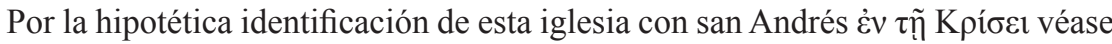
Janin, "La géographie ecclésiastique”, 30. $343 \mathrm{C}$.

Esto parece estar implicado por Jerónimo, Contra Vigilantium, PL 23,

23 Cronicón Pascual 569, 12-18, Whitby 1989, 53: "And in the same year [406 d.C.] the remains of St. Samuel were conveyed to Constantinople by way of the Chalcedonian jetty [...] with Arcadius Augustus leading the way, and Anthemius, praetorian prefect and former consul, Aemilianis, city prefect and former consul, Aemilianus, city prefect, and all the senate [...]".

24 Jerónimo, Contra Vigilantium, PL 23, 343C: "una gran multitud del mundo".

25 Poco se sabe sobre el muelle de Calcedón (o escalera de Calcedonia), un muelle creado para servir a los habitantes de Calcedonia para el transporte marítimo. Janin la identifica como parte de Portus Prosphorianus. Janin 1964, 235 .

26 La elección de la Gran Iglesia como lugar (temporal) de custodia de los restos del profeta parece inesperada si pensamos que la iglesia debe haber sufrido, al menos en parte, daños por el incendio del 404 d.C. (Cronicón pascual 568, 14-17, Whitby 1989, 54: "these remains were laid to rest for a certain time in the most holy Great Church). Unos años más tarde, el 7 de noviembre de 410 d.C., los restos fueron trasladados de la Gran Iglesia y trasladados a una iglesia 
octubre de 411 d.C., sus restos fueron retirados del templo de Santa Sofía, y fueron situados en un templo de peregrinación recién construido, cerca del templo de San Juan el Bautista en el barrio Hebdomon. ${ }^{27}$

Puede ser más que una coincidencia que bajo el reino de Teodosio II (408-450 d.C.), los restos añadidos de personajes bíblicos del Antiguo Testamento hayan llegado a Constantinopla. ${ }^{28} \mathrm{~A}$ finales de agosto u octubre de 415 d.C., los cuerpos de José, hijo del patriarca Jacob del Antiguo Testamento, y de Zacarías, padre de Juan el Bautista, llegaron a Basileuousa polis, una vez más, a través del muelle de Constantinopla. Como describe

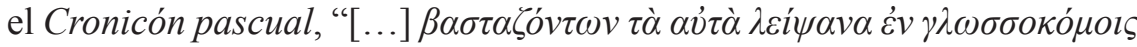

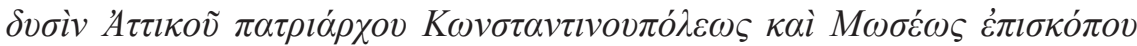

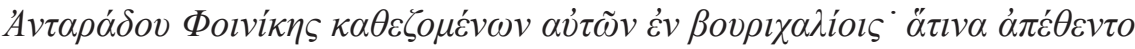

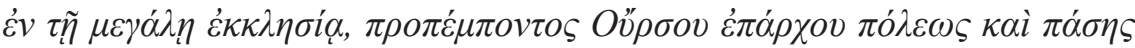
$\tau \tilde{\eta} \varsigma \sigma v \gamma \kappa \lambda \dot{\eta} \tau o v " .{ }^{29} \mathrm{El}$ momento de la recuperación, posiblemente motivado por el clero que acompañó a las reliquias, no pudo haber sido más adecuado, ya que las reliquias llegaron al momento mismo de la inauguración del templo de Santa Sofía en Constantinopla el 10 de octubre de 415 d.C. ${ }^{30}$

construida recientemente para contener los restos del Profeta en el Hebdomon. Esta iglesia sufrió daños considerables durante el terremoto del 14 de diciembre de 557 d.C., Janin 1969, 31.

27 Según Teófanes el Confesor, esta iglesia sufrió daños considerables durante el terremoto del 14 de diciembre de 557 d.C.: Chronographia 231, 1720: "In particular, there collapsed churches and the area beyond the Hebdomon, namely St. Samuel, the Holy Mother of God of Petalas, St. Vincent, and many church altars and ciboria between the Golden Gate and Rhesion". Mango sugiere que, dado que la iglesia no se refiere a ninguna fuente posterior, puede que no haya sido construida en absoluto, pero fue una fantasía. C. Mango, The Chronicle of Theophanes Confessor. Byzantine and Near Eastern History, AD 284-813, Oxford, 1997, 340, nota 3.

Maraval, Lieux saints et pelerinages d'Orient, 94.

29 Cronicón pascual 572, Whitby, Chronicon Paschale, 63: "The same remains were borne in two caskets by Atticus, patriarch of Constantinople, and Moses, bishop of Antaradus in Phoenicia, the two men sitting in carriages; these were laid to rest in the Great Church, with Ursus, city prefect, in attendance and all the senate".

30 Para la fecha dada por el Cronicón pascual sobre la llegada de la reliquia véase, Whitby, Chronicon Paschale, 64, nota 218. 
La introducción de los restos desde varias partes del imperio se convirtió en una estándar para Constantinopla. El nuevo político y creciente centro cristiano del Oriente necesitaba sufficientes reliquias para competir con los otros centros religiosos del Mediterráneo. Crisóstomo mismo, supervisó en Constantinopla, durante su breve período como Arzobispo, el curso de la recuperación de al menos dos mártires importantes. ${ }^{31}$ En contraste con la ciudad de Antioquía, los restos de estos mártires generalmente permanecían dentro de la ciudad, en templos de peregrinacion dedicados a ellos. Bajo el arzobispado de Juan Crisóstomo, dos emperadores, Constantino el Grande y Teodosio el Grande, fueron enterrados en el templo de los Santos Apóstoles, con la r reliquias de los Apóstoles Lucas, Andrés y Timoteo. ${ }^{32} \mathrm{El}$ antiguo prejuicio romano y la tradición contra las reliquias no se aplicaron al nuevo mundo bizantino para hombres y mujeres que conservan su santidad y pureza incluso después de la muerte.

En este contexto más general, Crisóstomo, un predicador con una tendencia y contenido ético, utilizó el honor de los mártires como medio para cristianizar el nuevo imperio. Los mártires le proporcionaron a Crisóstomo muchos modelos espirituales que podían usar para modificar su nueva congregación, con la promesa de beneficios morales y espirituales. La veneración de los mártires también proporcionó beneficios tangibles para la protección de los cristianos. Crisóstomo utilizó los mártires además para atacar las herejías y los enemigos de la Iglesia. El honor a los mártires contribuyó significativamente a la cristianización de Constantinopla y también desarolló la teología de Crisóstomo sobre el "martirio", una teología que era consistente con las tradiciones patrísticas anteriores, pero agregó algunos conceptos adicionales, basados en estas experiencias de los mártires, hombres y mujeres.

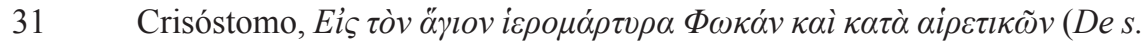
hieromartyre Phoca et contra haereticos, PG 48, 850-851), PG 50, col. 699-706,

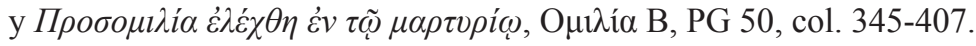

32 Wendy Mayer, John Chrysostom. The Early Church Fathers, London, 2000, 21. 


\section{El concepto de "martirio" según Juan Crisóstomo}

Al enseñar sobre el "martirio", Crisóstomo enfatiza la necesidad de su rebaño de imitar a los mártires lo mejor que pueda. La imitación es la forma más honorable a ellos. Sin embargo, del contexto general de la enseñanza de Crisóstomo estaban ausentes las oportunidades de persecución y de la muerte sufrida de los cristianos, que disfrutaron los cristianos de los primeros siglos. Por lo tanto, Crisóstomo gira el mensaje de los mártires para que coincida con el propósito ético de su enseñanza. En sus sermones, los mártires confían menos a la creencia en la superación de la muerte por Cristo, y más a la necesidad del comportamiento moral cristiano.

Crisóstomo vivió en un período relativamente tranquilo del cristianismo. Sin embargo, aunque la Iglesia se encontraba en un período de independencia religiosa, mantuvo activamente el vínculo con su pasado perseguido. El aumento del honor a los mártires a mediados del siglo IV, aseguró que aquellos cristianos, hombres y mujeres, que fueron torturados y asesinados durante las persecuciones, se mantendrían intactos y vivos en la memoria de los creyentes. Se establecieron fiestas anuales para celebrar el cumpleaños del mártir; ese día fue para celebrar y traer a la memoria del creyente el día terrenal de la muerte del mártir y su renacimiento en el firmamento celestial. Estos eventos variaron de un lugar a otro, e incluyeron la letanía de las reliquias de los mártires, los oficios religiosos sobre lápidas (arcosolia), la lectura de la pasión (passsio) del mártir, y, al final, el discuro de diversos sermones. Estos eventos públicos a menudo atrajeron grandes y variadas multitudes de creyentes, incluidos hombres y mujeres, jóvenes y viejos, alfabetizados y analfabetos. ${ }^{33}$ Fue en estos casos y para estas personas / mártires que Crisóstomo enseñó acerca de su vida y su presencia en la Iglesia.

La intensificación del honor a los mártires en las comunidades cristianas, promovió la recolección, división, y recuperación de reliquias de los mártires: es decir, su sangre, huesos y cenizas. Incluso los objetos materiales que habían estado en contacto con el santuario del mártir, se mantenían con gran distinción, como el polvo raspado por las tumbas, el aceite que había tirado en los huesos o la tela que había sido impregnada en una tumba. Los mártires murieron por su fe en Dios, y dar la propria vida a Dios, a la conciencia de muchos cristianos, fue el sacrificio supremo a Dios. 
Lejos del momento histórico del martirio (a veces unos trescientos años), el papel de Crisóstomo fue revivir el "martirio" en la mente del creyente a través de sus homilías y sermones. Tratando de despertar los sentimientos de la audiencia e inspirar el asombro y la admiración hacia los mártires, Crisóstomo describió el "martirio" con detalles vividos. Usando varias palabras y expresiones para representar múltiples escenas de mártires dentro de la mente de cada oyente, describía los cuerpos de los mártires como carne arada en la tierra, costillas cortadas, entrañas desgarradas, vértebras trituradas, sangre fluida, carne derretida, y demás. ${ }^{34}$ $\mathrm{Y}$, sin embargo, dentro de este pintoresco retrato del sufrimiento humano, Crisóstomo logró formular en verso, la romantización del cuerpo del mártir con expresiones como: cuerpos manchados de sangre que brillan como brillantes rayos amarillos oscuros del sol de la mañana, mártires acostados sobre brasa caliente, como si estuvieran recostados en una cama suave con flores, hombres cuya lengua está cortada tienen una habla aún más hermosa y espiritual, y demás. ${ }^{35}$

El proceso de abstracción, exacerbación e imitación, que se encuentra en la forma en que Crisóstomo alienta a su rebaño, a través de sus sermones, forma un imagen mental del "martirio", que se ve como una representación de la mente. En una homilía, refiriéndose al mártir Barlaam, Crisóstomo alienta a la audiencia a hacer precisamente eso. ${ }^{36}$ La Passio, alejada del tiempo y el lugar del martirio, y reposicionada en la mente de todos, el público realiza un evento de este tiempo, hablando directa e instantáneamente a personas de todos los géneros y sexos. Con tonos bajos neoplatónicos, Crisóstomo exhorta a su audiencia a aceptar la imagen del mártir en su memoria, y a verla como una imagen de un modelo de sacrificio y virtud. Esta internalización del mártir, junto con el creyente,

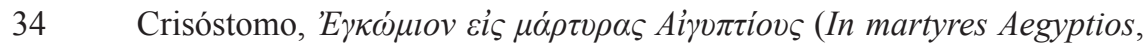
BHG 1192, CPG2 4363) 2, PG 50, col. 694 y Mayer, Cult of the Saints, 212, 221-221.

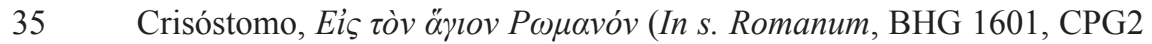
4352), PG 50, 605-618. Mayer, Cult of the Saints, 228-237.

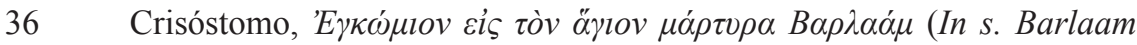
martyrem, BHG 222, CPG2 4361) 12, PG 50, col. 675-682, Mayer, Cult of the Saints, 188. 
trasmuta el cristiano y lo transforma en un modelo vivo del mártir. ${ }^{37}$

Para Crisóstomo, la memoria de los mártires es una "pintura"

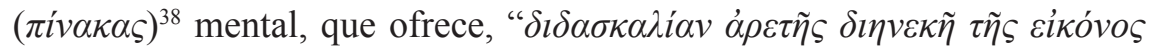

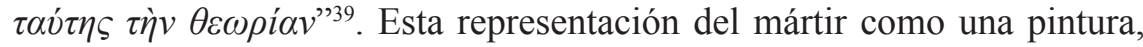
refleja una comprensión de la memoria del mártir que fue popular en la antigüedad tardía: los recuerdos eran imágenes pintadas o impresas en la mente del hombre como si estuvieran en un plato de cera. ${ }^{40}$ Aquí, la importancia del martirio se comunica a través del recuerdo de las «cosas», es decir, el cuerpo que ha sido sometido al martirio, los métodos de persecución y las herramientas de tortura, representados dentro del intelecto. El recuerdo de estas imágenes dramáticas, putativas e intersubjetivas puede ser un punto de tensión emocional. El público que incorpora la imagen mental del mártir, adopta el mundo emocional del mártir, y así deja la influencia de la memoria para dar forma a su propio juicio y curso moral.

El día de la festividad de un mártir se convierte en una sala de enseñanza para Crisóstomo, los mártires se convierten en maestros y su predicación se convierte en una herramienta de educación religiosa. La audiencia de los cristianos se para ante el monumento del mártir, presentado a los pies del mártir, tal como se enseñaría a un alumno a los pies de su maestro. Refiriéndose a la idea retórica del lenguaje corporal, Crisóstomo retrata a los mártires como maetros insuperables, grandes filósofos y predicadores de la fe. En una homilía dirigida a Antioquía en la última década del siglo IV, Crisóstomo desarrolla la idea del lenguaje corporal natural para describir el martirio como una forma de enseñar, y

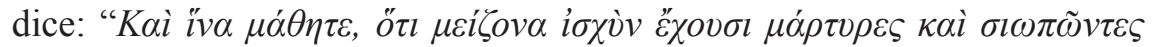

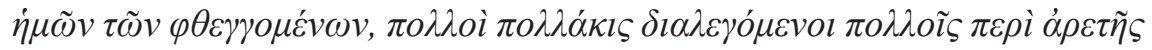

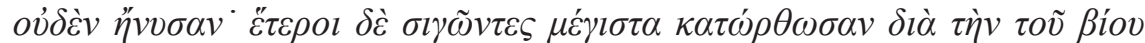

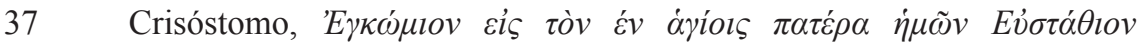

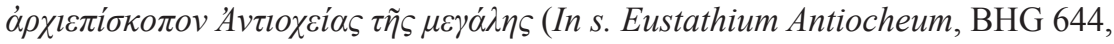
CPG2 4352), PG 50, col. 597-606, Mayer, Cult of the Saints, 54.

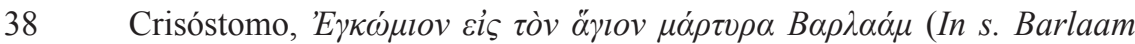
martyrem, BHG 222, CPG2 4361), PG 50, col. 675-682, Mayer Cult of the Saints, 188.

39 Ibíd.

40 M. J. Carruthers, The Book of Memory: A Study of Memory in Medieval Culture, Cambridge, 1990, 21-24. 


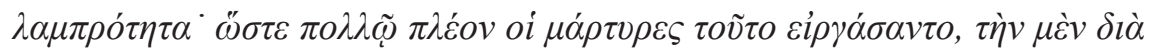

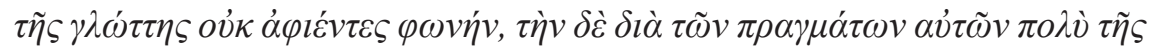

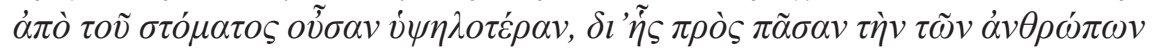

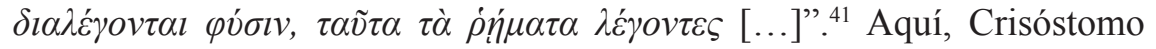
cita lado a lado la fe del mártir como la elocuencia de la meditación filosófica. Usando la habilidad retórica para contrarrestar sus posiciones de predicación, él describe a los mártires como filósofos supremos. Los ejemplos tácitos de los mártires son más efectivos para alentar el camino de la virtud cristiana que los argumentos verbales de los filósofos. Si la retórica es el arte de la comunicación convincente, entonces los mártires son oradores por excelencia. Los mártires hablan con su cuerpo y articulan sus voces con sus obras. ${ }^{42}$

Para Crisóstomo, el recuerdo de los mártires es "necesario", porque restaura el cuadro a su esplendor original, evitando así que la memoria se difumine o se apague con el tiempo. Además, la memoria de los mártires es «útil» porque es una forma de educación y enseñanza moral. Crisóstomo recomienda a su rebaño usar la memoria de los mártires para imitarlos aceptándolos como modelos y mentores. ${ }^{43}$

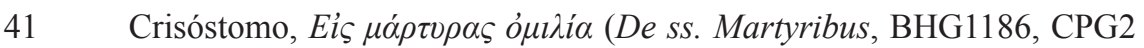
4357), PG 50 col. 645-654, J. Leemans, "Let us die that we may live": Greek Homilies on Christian Martyrs from Asia Minor, Palestine and Syria (c. AD 350-AD 450), London, 2003, 119: "To teach you that, even when silent, martyrs are louder in volume than we when we speak, when time after time many have preached to many others on the topic of virtue, they have achieved nothing; yet others, though silent, have achieved major successes through the splendour of their life. Consequently, the martyrs have affected this to a greater degree, uttering voice not with their tongue, but with their deeds - a voice far superior to that which comes from the mouth. Through it they preach to humankind's whole nature, speaking the following words $[\ldots]$ "

42 Martin, "Golden Mouths and Speaking Bodies", 12.

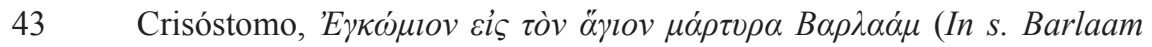
martyrem, BHG 222, CPG2 4361), PG 50, 675-682, Mayer, John Chrysostom, 188-189. 


\section{El martirio como "sacrificio"}

Crisóstomo encarna esta dimensión sacrificial en su teología del "martirio", viéndolo como una imitación del sacrificio de Cristo. ${ }^{44}$ En su sermón sobre San Ignacio de Antioquía, Crisóstomo afirma que los apóstoles Pedro y Pablo, e Ignacio, fueron sacrificados en la misma ciudad

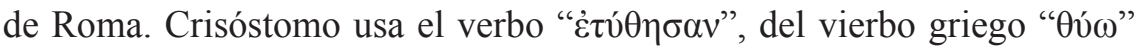
(sacrificar), una palabra común que incluye el concepto de "sacrificio", y que podría aplicarse a los rituales de sacrificio, de adoración pagana, la Pascua judía y la crucifixión de Cristo. Las muertes de Pedro, Pablo e Ignacio en Roma nuevamente proclamaron y llevaron a cabo el sacrificio que Cristo había hecho en nombre de esta ciudad. Según Crisóstomo, todos estos sacrificios de los mártires fueron imitaciones de aquel sacrificio hecho

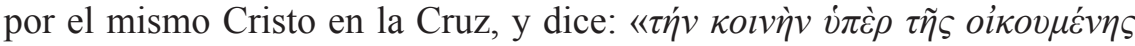

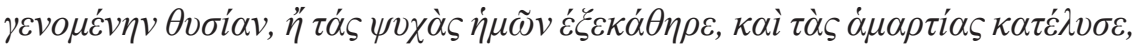

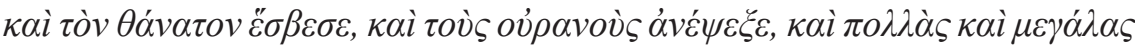
$\dot{\eta} \mu l v \dot{\varepsilon} \lambda \pi i \delta \alpha \varsigma \dot{v} \pi \dot{\varepsilon} \delta \varepsilon l \xi \xi$, $\kappa \alpha i ̀ ~ \tau \grave{\alpha} \dot{\alpha} \lambda \lambda \alpha \pi \dot{\alpha} v \tau \alpha \kappa \alpha \tau \varepsilon \sigma \kappa \varepsilon v \dot{\alpha} \alpha \sigma \varepsilon v \gg{ }^{45}$. Su muerte fue un "sacrificio común" con las consecuencias de restaurar la esperanza, purificar el alma, perdonar y eliminar los pecados, y restaurar el camino a la eternidad.

Aunque Crisóstomo consideraba la muerte de un mártir como un acto de "sacrificio", atribuía varios significados diferentes a ese "sacrificio". En su mismo sermón sobre San Ignacio, afirma que los sacrificios de los apóstoles Pedro y Pablo, y de Ignacio, fueron sacrificios de purificación. Esta noción de sacrificio como "purificación" también se puede encontrar en otro sermón que se refiere al mártir Dróside, de Antioquía. Crisóstomo le dice a sus oyentes que los ejecutores de Dróside la prendieron fuego y que el humo que emitía su cuerpo era como un sacrificio de purificación, que purificaba el aire del humo de la idolatría. ${ }^{46}$ Por lo tanto, según Crisóstomo, el martirio podría ser un acto de sacrificio de "purificación", que luchó contra la idolatría y allanaba el camino para el cristianismo del estado.

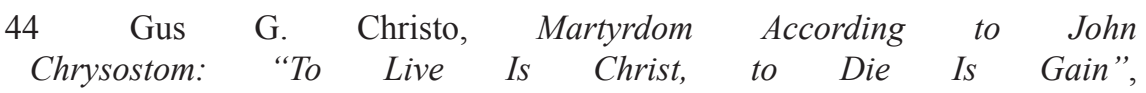
Lewiston, 1997, 35-37

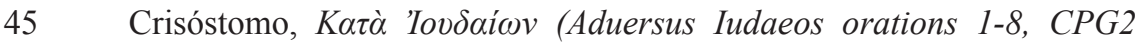
4327), 7, 2, PG 48, 918-919.

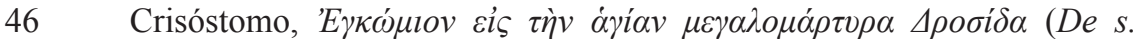
martyre Droside, BHG 560, CPG2 4362) 4, PG 50, 689. 
Además, y según Crisóstomo, fuera de la purificación, la muerte de un mártir podría beneficiar a la comunidad en general de varias maneras, al valor del arrepentimiento o expiación. En los primeros años de su sacerdocio en Antioquía, Crisóstomo dirigió un sermón para los mártires locales, Juventino y Maximino, enfatizando la idea de que su muerte de alguna manera cubría y evitaba los pecados de la ciudad. Juventino y Maximino fueron mártires relativamente recientes, que fueron ejecutados durante la estadía de Julián en Antioquía, del 361 al 363 d.C. Eran oficiales del ejército imperial y venerables cristianos, que no aprobaban el renacimiento del espíritu pagano por Julián, y eran lo suficientemente valientes como para expresar su oposición, como dice Teodoreto, con un "dialecto entusiasta". ${ }^{47}$ Cuando Julián ordenó su ejecución para contrarrestar el espíritu de descaro que expresaban, estos mártires vieron este gesto como una forma de acercarse a la muerte de mártires. Crisóstomo dice en su sermón que estos dos soldados fieles afirmaron que su muerte inminente también sería un acto de expiación por los pecados de sus compañeros soldados, que se reconciliaron con el espíritu de Julián, y continúa diciendo: como Dios ama a la humanidad, también perdonaría las malas acciones de sus amigos a través de su propio sacrificio. En este punto, Crisóstomo ha colocado a los mártires en paralelo al canto de los tres niños judíos que Nabucodonosor arrojó al horno encendido. En este canto, que se encuentra en el tercer capítulo del profeta Daniel, los tres sacerdotes rezan a Dios para que considere su muerte como un sustituto de la muerte de toros y carneros, y también mostrar misericordia a otras personas por su humilde sacrificio a Él. De la misma manera, los mártires Juventino y Maximino fueron expiados, en su sacrificio, por algunos de los sufrimientos causados por Julián en la ciudad de Antioquía, y esta expiación se extendió a otros que sufrieron tales sufrimientos, pero no al propio emperador. ${ }^{48}$

Crisóstomo afirma que el "martirio" creó una bendición horizontal, en el sentido de que los beneficios que recibió el mártir a través de este sacrificio también beneficiarían al resto de la humanidad. Sin embargo, según él, esta dimensión horizontal es simplemente un efecto secundario del propósito principal del martirio, que está dirigido a Dios. Explica esta

47 Teodoreto, Historia Eclesiástica, 3, 11.

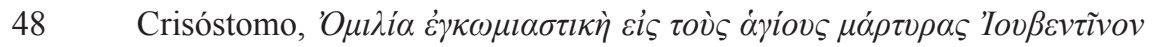

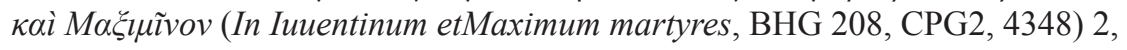
PG 50, 575 
idea en uno de sus sermones dirigidos al mártir Julián, obispo de Cilicia, que predicó en Antioquía. Los restos de Julián, que fue martirizado de ahogamiento en el mar, fueron llevados a Antioquía para una celebración de dos días. ${ }^{49}$ Crisóstomo, refiriéndose a su iglesia que fue reunida por esta razón, dice que aunque la multitud de estos creyentes se unieron para honrar a los mártires, estos mártires no fueron sacrificados por ellos, sino

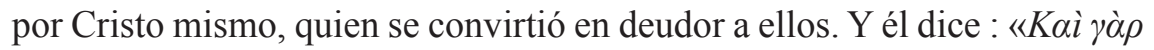

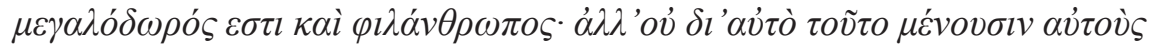

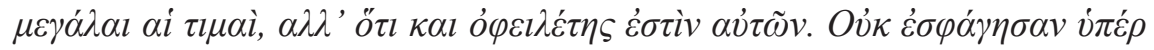

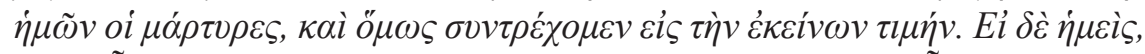

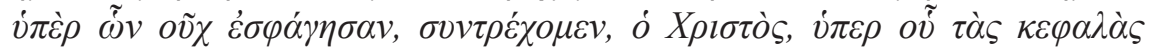

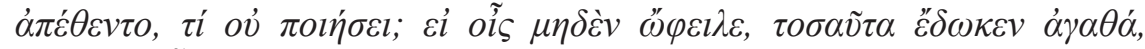

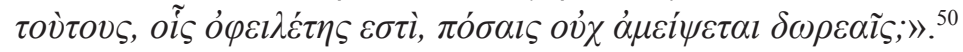

El sufrimiento de los mártires mejora la muerte sacrificial, y cuanto mayor es el sufrimiento del mártir durante su martirio, mayores son las recompensas que recibe de Dios. En su predicación al obispo de Cilicia Julián, Crisóstomo también se ocupa ampliamente de la tortura del mártir. Afirma que el sufrimiento de Julián fue algo especial de los otros mártires, en el sentido de que sufrió, no solo una pelea, sino muchas porque el juez que lo juzgó lo había interrogado repetidamente en la corte durante un año entero finalmente ordene su ejecución. Durante este año, Julián no solo fue interrogado, sino también agitado, y finalmente se mostró de una manera vergonzosa. Su encarcelamiento durante este tiempo hace que su martirio sea aún más dulce. De hecho, en el curso de su sermón, Crisóstomo compara a Julián con uno de sus compañeros de Cilicia, el apóstol Pablo, quien también soportó mucho durante su ministerio apostólico. ${ }^{51}$

49 J. Leemans, "Let Us Die that We May Live": Greek Homilies on Christian Martyrs from Asia Minor, Palestine and Syria (c. AD 350-AD 450), London, 2003, 127-128

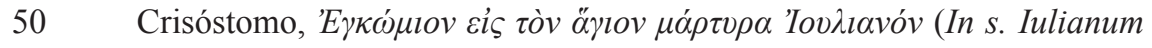
martyrem, BHG 967, CPG2, 4360), 1, PG 50, 667.

Ibíd. PG 50, 668-669. 


\section{El honor a las reliquias santas según Juan Crisóstomo}

Los mártires, según Crisóstomo, reinaban junto con Cristo en el firmamento celestial de Dios, pero también vivían al mismo tiempo en sus reliquias, en la esfera terrenal y espiritual de la Iglesia. Las reliquias de los mártires proporcionaron a la Iglesia un gran poder que podría ser utilizado para la elevación espiritual de los fieles, y la protección de la Iglesia por parte de sus diversos enemigos.

Además, las reliquias de los mártires, según Crisóstomo, también tenían una fuerza milagrosa sanadora, que los hizo invaluables en la conciencia de los fieles. En su sermón sobre la mártir Dróside, Crisóstomo afirma que el polvo y las cenizas, que quedaron de la combustión de su cuerpo, se hicieron más preciosos que cualquier oro, piedra preciosa o perfume. Estos datos, continúa Crisóstomo, aunque tenían un valor valioso para la vida mundana, no tenían absolutamente ninguna superioridad ni valor para la vida espiritual. Las reliquias de los mártires, por el contrario, tenían el poder de curar todo tipo de pasiones y enfermedades, incluso para resucitar a los muertos. Por supuesto, él admite en su propio sermón, entonces, que había pasado suficiente tiempo desde el poder milagroso, no resucitó ningún muerto. ${ }^{52}$ En conclusión, Crisóstomo pone más énfasis en los valores espirituales de estos remanentes que en los milagros tangibles asociados con ellos.

Al predicar con la presencia de los restos de los mártires, Crisóstomo a menudo se refería a ellos, caracterizándolos como un "depósito" de valores espirituales, que nunca podrían ser vaciados debido a la constante provisión por parte de Cristo mismo. Refiriéndose a San Ignacio de Antioquía, Crisóstomo predicaba que este "depósito" proporciona a los asistentes las bendiciones espirituales infinitas, como la fe, los pensamientos virtuosos y el coraje..$^{53}$ Las reliquias de un mártir, aunque dan muchas bendiciones espirituales al creyente, y en general a la Iglesia, pero también brindan la protección del mártir a la congregación. Crisóstomo sabía bien que el cuidado de la vida urbana podría haber llevado al cristiano a salir de la calle de la templanza. Propuso a su rebaño vigilar regularmente en los

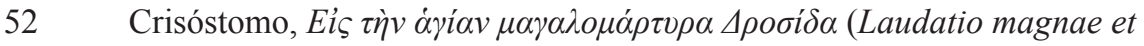
sanctae martyris Drosidis, BHG 560, CPG2 4362), 4, PG 50, col. 683-694, col. 689.

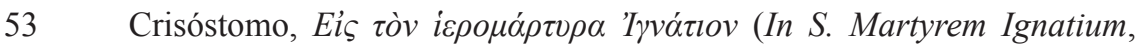
BHG 816, CPG2 4351) 5, PG 50, col. 594-595. 
restos de los mártires para que su intelecto se centre constantemente en el comportamiento virtuoso. A través de la adoración constante de los restos, el cristiano recibiría las bendiciones espirituales necesarias para dar gracias constantemente a Dios y estar protegido de las diversas tentaciones externas.

En la mente de Crisóstomo, los mártires realmente cumplen un papel mediador entre Dios y la Iglesia, debido a la encarnación y al sacrificio supremo de su Hijo. Según él, los mártires conceden continuamente las bendiciones de Dios a su rebaño solo cuando los cristianos los honran con su presencia e imitación constantes. En uno de sus sermones para los mártires Macabeos, Crisóstomo compara a los que se han reunido en la fiesta con la viuda que dio los dos céntimos, como lo describe en el

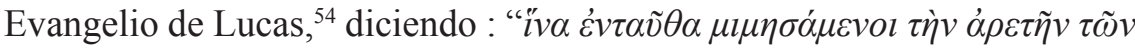

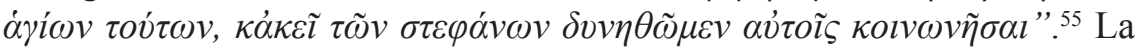
donación del honor de la Iglesia a los mártires es pequeña e insignificante, pero aún así, sigue siendo un medio para obtener una tremenda bendición espiritual. Los mártires no olvidan recompensar a quienes se reunieron para honrarlos, ya que Dios los bendijo generosamente en vista de su sacrificio supremo a Él..$^{56}$

En su sermon sobre los dos mártires y oficiales del Estado, Juventino y Maximino, quienes fueron condenados por las autoridades por traición, Crisóstomo compara la relación entre Dios y esos mártires con la de un

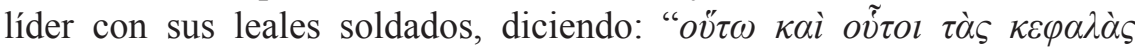

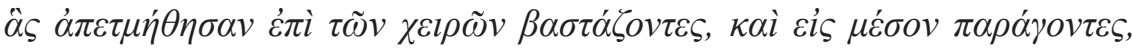

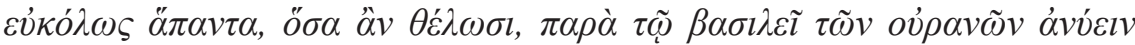
$\delta v ́ v \alpha v \tau \alpha l, .{ }^{57}$ Los mártires, que residen en las reliquias, están entre Dios y

$54 \quad$ Lc. 21, 1-4: "Y mirando, Jesús vio a los ricos que echaban sus ofrendas en el arca del tesoro.Y vio también a una viuda pobre que echaba allí dos blancas. Entonces dijo: En verdad os digo que esta viuda pobre echó más que todos. Porque todos estos, de lo que les sobra echaron para las ofrendas de Dios; mas ella, de su pobreza, echó todo el sustento que tenía.

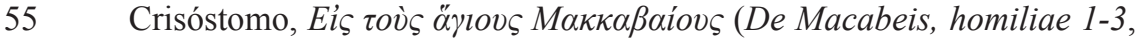
BHG 1008-1010, CPG2 4354) 1, 3, PG 50, col. 622.

Ibid. 2, 1, PG 50, col. 623.

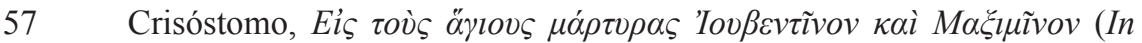
Iunentinum et Maximum martyres, BHG 975, CPG2 4349), 3, PG 50, col. 576. 
la Iglesia, como canales de bendición, y a los que se puede acceder, cuando los cristianos señalizan sus necesidades a través del honor relativo. Incluso el acercamiento al santuario de las reliquias del mártir, podría compararse con el acercamiento del creyente al trono de Dios. ${ }^{58}$ De esta manera, Crisóstomo utilizó el valor de los mártires para determinar su identidad en el rebaño con Dios, y por otro, determinar los enemigos de la Iglesia, proporcionando así una protección relativa en su congregación.

Durante su servicio episcopal en Antioquía, Crisóstomo se quejaba amargamente de la influencia de la comunidad judía en su congregación. ${ }^{59}$ Muchos cristianos participaron en las fiestas judías, borrando las líneas divisorias entre los dos rebaños. Un tema que complicó la situación y se centró en Antioquía fue la reciente adopción, por parte de los cristianos, del honor a los Macabeos, figuras de martirio de la tradición judía. Durante ese período, muchos creyentes, en la ciudad de Antioquía, veían la línea divisoria entre el cristianismo y el judaísmo de una manera relativamente eclipsada. Los ataques de Crisóstomo, a través de sus sermones y escritos hacia la comunidad judía de Antoquía, son famosos y conocidos, pero lo que es de gran interés es la forma en que usó los mártires como armas agresivas para frustrar la presencia de los judíos en la ciudad de Antioquía, y por extensión su influencia en la comunidad cristiana local. En su sermón, Adversus Judaeos, pronunciado el día de la celebración de un mártir, Crisóstomo, en lugar de proclamar en la fiesta de un mártir, indignado, aparentemente de episodios recientes, generalmente se refería a los elementos perversos de la religión judía; refiriendo sarcásticamente, que los mártires lo escucharían cada vez más para criticar a los judíos en lugar de alabar a sus propios martirios. ${ }^{60}$ Continuando, él afirma que los mártires tenían un odio especial contra los judíos, ya que los judíos eran culpables de la crucifixión de Cristo, a quien amaban y sacrificaban sus

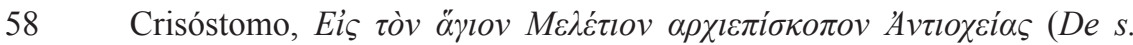
Meletio Antiocheno, BHG 1244, CPG2 4345), 3, PG 50, col. 520.

59 Robert L., Wilken, John Chrysostom and the Jews: Rhetoric and Reality in the Late 4th Century. The Transformation of the Classical Heritage, Berkeley, 1983, 123-127.

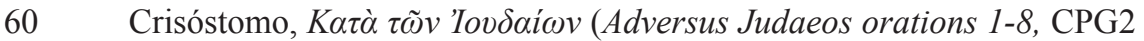
4327), 6, 1, PG 48, col. 904. 
vidas por Él. ${ }^{61}$

En otro su sermón, como diferencia a los oyentes cristianos de los judíos "enemigos y opositores", Crisóstomo se dirigió a su rebaño, alentándolos a usar el poder de los mártires para rechazar las imposiciones e influencias judías. Él señala que sí, tanto los cristianos como los judíos, están siguiendo el camino del ayuno, pero estas mismas formas no producen los mismos beneficios espirituales. También señala que tanto los mártires como los delincuentes fueron condenados por la misma muerte, pero solo los mártires obtuvieron la corona de la justicia, mientras que los delincuentes fueron condenados eternamente. De esta manera, el ayuno de los cristianos, que es una forma de sacrificio y humildad de la persona que ayuna, eleva espiritualmente el alma del creyente, pero el ayuno de los judíos simplemente aumenta su culpa en el acto de vergüenza que hicieron en el pasado. ${ }^{62}$

En otro sermón, que también se refiere a la comunidad judía, Crisóstomo afirma que los judíos no pueden ser considerados "santos" porque poseen solo la tradición de las Escrituras. Y aclara diciendo que en los días de persecución, aunque los jueces condenaron a los mártires "santos", su relación con los mártires, sin embargo, no los convirtió automáticamente en santos. Los jueces condenaron a los mártires por su propia convicción, y los judíos violaron las Escrituras a través de una brutal mala interpretación ${ }^{63}$.

Sin embargo, una vez que se convirtió en arzobispo de Constantinopla, la amenaza judía no fue tan urgente y crucial, como lo fue en Antioquía. Además de la amenaza de la coexistencia lujosa de los ciudadanos de la Basileuousa polis, Crisóstomo también tuvo que enfrentar las persistentes simpatías de su rebaño a la enseñanza de Arrio. Crisóstomo como arzobispo de Constantinopla utilizó una vez más la presencia de mártires, ofrecida como otra forma en la que podía renunciar al arrianismo. En su homilía en honor al mártir Focas, Crisóstomo usa la mayor parte de esta homilía para desafiar a los herejes. En la segunda parte de su sermón, que era diferente a la vida del mártir, Crisóstomo explica a sus oyentes por qué Dios Padre e Hijo son compatibles con diferentes personas. Es interesante que use

61 Ibíd. 6, 1, PG 48, col. 905.

62 Ibid. 1, 5, PG 48, 850-851.

63 PG 48, 850-851. 
el significado metafórico del término "atleta", que usaba tan a menudo cuando se refería a los mártires, para describir su propia presencia como un "atleta", que siempre estaba listo a través de sus sermones para luchar por los enemigos de la Iglesia, los herejes. ${ }^{64}$ Usando la noción de "atleta", Crisóstomo parece asociarse aún con este trabajo de mártires. Aunque este sermón reprende la enseñanza de Arrio, Crisóstomo parece ser bastante comprensivo con los propios seguidores de Arrio. Él afirma explícitamente que ama a los herejes y no desea expulsarlos. Solo quiere borrar sus falsas creencias y guiarlos a la verdad. ${ }^{65}$ Este enfoque de la simpatía y compasión de Crisóstomo hacia los seguidores de Arrio que quedan, hace que alguien se pregunte, si realmente los percibió como una amenaza real para la Iglesia, o los compraró con la mayor amenaza de esta presencia judía en el Estado, o incluso con el abuso de la lujosa forma de vivir de sus conciudadanos en la Basileuousa polis, o incluso si él específicamente buscó el favor de los partidarios de Arrio que estaban en la gente ese día.

Además, Crisóstomo creía que las reliquias y el honor a los mártires serían los medios por los cuales conquistaría la cristianización del Estado. Los enemigos del cristianismo eran numerosos, pero Cristo ganaría la victoria usando a sus mártires. De hecho, en su carta al presbítero Rufino, Crisóstomo parece considerar la posesión de los restos como una condición previa para el esfuerzo misionero de la cristianización del Basileuousa y del Estado. Rufino, al tratar de establecer una comunidad cristiana en el área rural, recibió una carta de Crisóstomo, quien, a través de ella, lo felicitaba por sus esfuerzos, y lo alentó diciendo, que estaba ganando muchas coronas por este trabajo que hizo. Y la presencia de los restos que tendrían lugar a través de uno de sus conocidos le daría la posibilidad de protección espiritual contra los enemigos de la Iglesia ${ }^{66} \mathrm{Y}$ continúa en la misma carta y dice que todas las comunidades cristianas necesitaban

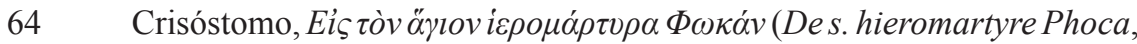

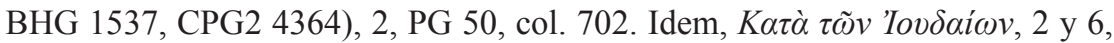
donde él usa el mismo transporte para describir sus batallas con la comunidad judía.

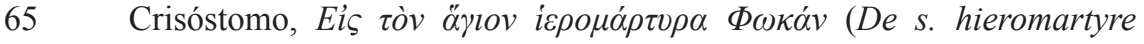
Phoca, BHG 1537, CPG2 4364), 2, PG 50, 701.

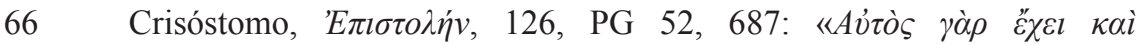

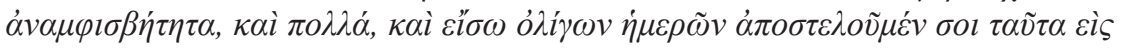

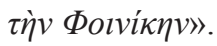


la protección de las reliquias de los mártires dentro de su cuerpo para su crecimiento espiritual.

Mientras supervisaba la construcción de los diversos templos de peregrinación en la capital bizantina y la recuperación de reliquias de los mártires desde diversas partes del Estado, Crisóstomo vio sus esfuerzos para cumplir su propósito, es decir, la creación de una sociedad cristiana organizada, justificados. En el año 401 d.C., presentó en procesión las recién llegadas reliquias de un mártir en Constantinopla, y durante su sermón que declamó aquel día, confirmó en su rebaño, que estaba en un buen estado psicológico, diciendo que el mundo estaba en paz, los demonios estaban huyendo, incluso la Emperatriz misma [Eudoxia] caminaba humildemente al lado de las reliquias del mártir. Crisóstomo probablemente sintió que todos estos años predicando la moralidad del cristianismo habían comenzado a dar algunos frutos poderosos. La mujer más fuerte del Estado, Augusta Eudoxia, adoptó el modo de la abstinencia moral promovido por Crisóstomo, por el amor a los mártires y su dedicación al honor de ellos. Desafortunadamente, dos años después, Crisóstomo y Eudoxia cayeron en disensión, debido a la vida extravagante de la riqueza, la opulencia y la vida disoluta de la emperatriz. Eudoxia se le opuso porque se refería en sus sermones sobre las supuestas mujeres que mostraban su riqueza y su lujo como indignidades e insultos personales ${ }^{67}$ Cuando Crisóstomo cayó en desgracia debido a estas declaraciones, sus oponentes encontraron la oportunidad de enviarlo al exilio en el 403 d.C., donde después de algún tiempo, en el 407 d.C. él falleció lejos de su trono.

67 La investigación histórica, sin embargo, considera este texto falso. De hecho, los estudiosos modernos creen que el texto se rompió deliberadamente para servir a los propósitos de los oponentes de Crisóstomo. La misma investigación, sin embargo, ha revelado que los primeros historiadores que describieron este hecho no mencionan ningún tipo de discurso, por lo que se considera más adelante. Por la tensa relación entre Crisóstomo y Eudoxia, así como la literatura de investigación sobre la ilegalidad del texto anterior, véase, Holum, Kenneth G., 1982, Theodosian Empresses: Women and Imperial Dominion in Late Antiquity, Berkeley, 1982, 70-76. 


\section{Conclusión}

En conclusión, el valor de los mártires es un aspecto de la historia de la adoración de la Iglesia; pero esta historia, como todas las historias del mundo, está hecha de condiciones y perspectivas. Un análisis de la cuestión del honor a los mártires y su evolución conduce a otro enfoque histórico que se relaciona con la forma en que los jerarcas de la Iglesia del siglo $\mathrm{V}$ ayudaron a su rebaño a obtener una identidad cristiana adecuada basada en las acciones de sus mártires. de los primeros siglos cristianos.

\section{REFERENCIAS BIBLIOGRÁFICAS}

\section{Fuentes}

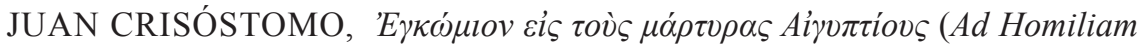
in martyres Aegyptios), PG 50, col. 693-698

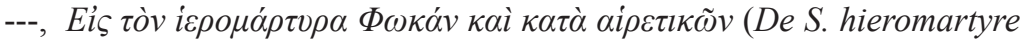
Phoca et contra haereticos), PG 50, col. 699-706.

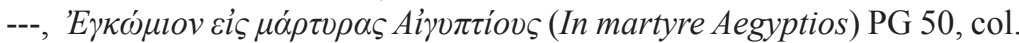
695-698.

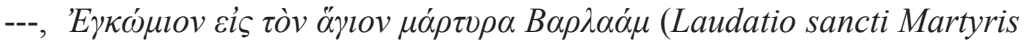
Barlaam) PG 50, col. 675-682

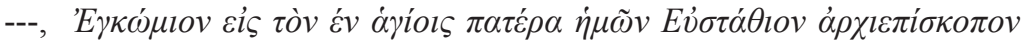

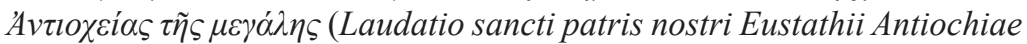
Magnae archiepiscopi), PG 50, col. 597-606.

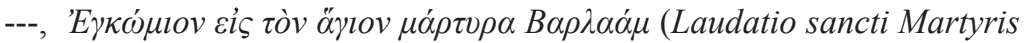
Barlaam), PG 50, col. 675-682.

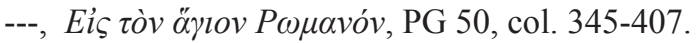

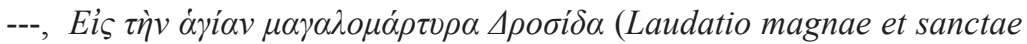
martyris Drosidis), 4, PG 50, col. 683-694.

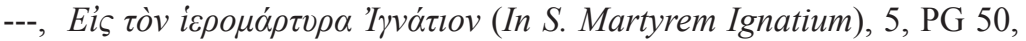
col. 587-596.

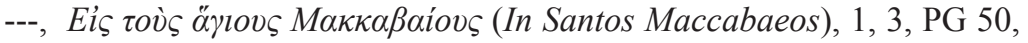
col. 617-624.

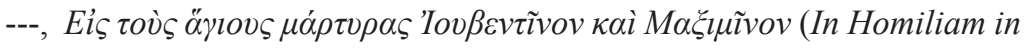
SS. Martyres Juventinum et Maximinum), 3, PG 50, col. 571-578.

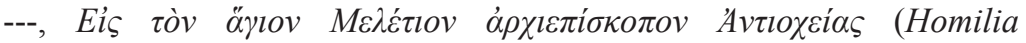
encomiastica in S. Patrem nostrum Meletium, Archiepiscorum Magnae Antiochiae), 3, PG 50, col. 515-520.

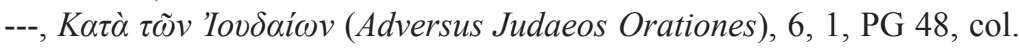
843-945. 
TEODORETO DE CIRO, Historia Ecclesiatica, en J.-P. Migne, Patrologia graeca (PG), París 1857 (82, col. 879-1279).

TEÓFANES EL CONFESOR, Chronographia en Cyril Mango, The Chronicle of Theophanes Confessor. Byzantine and Near Eastern History, AD 284813. Oxford 1997.

\section{Bibliografía}

CARRUTHERS, M. J. (1990), The Book of Memory: A Study of Memory in Medieval Culture, Cambridge.

DAGRON, G. (1984), Naissance d'une capitale. Constantinople et ses institutions de 330 à 451, París.

DELEHAYE, H. (1902), Synaxarium Ecclesiae Constantinopolitanae, Société de Bollandistes, Bruxelles.

DOWNEY, G. (1963), Ancient Antioch, Princeton.

EBERSOLT, J. (1921), Sanctuaires de Byzance. Recherches sur les anciens trésors des églises de Constantinople, París.

JANIN, R. (1964), Constantinople Byzantine. Développement urbain et répertoire topographique, París.

---, (1969), "La géographie ecclésiastique de l'Empire byzantine", vol. I, "Le Siège de Constantinople et le Patriarcat oecuménique", vol. III, "Les églises et les monastères", París.

JONES, A.H.M. (1953), "St. John Chrysostom's Parentage and Education”, The Harvard Theological Review, 46(3), 171-173.

KELLY, J.N.D. (1995), Golden Mouth. The Story of John Chrysostom: Ascetic, Preacher, Bishop, London.

KLEIN, HOLGER A. (2006), "Sacred relics and Imperial Ceremonies at the great Palace of Constantinople", BYZAS 5, 77-99.

KOENEN, U. (1996), "Symbol und Zierde auf dem Diadem und Kronreif spätantiker und byzantinischer Herrscher und die Kreuzauffindungslegende bei Ambrosius", Jahrbuch für Antike und Christentum 39, 170-199.

KRAUTHEIMER, R. (1987), Three Christian Capitals, California.

LEEMANS, J. "Let Us Die that We May Live:" Greek Homilies on Christian Martyrs from Asia Minor, Palestine and Syria (c. AD 350-AD 450), London, 2003.

MANGO, C. (1990), "Constantine's Mausoleum and the Translation of Relics", Byzantinische Zeitschrift 83, 51-62.

--- (1997), The Chronicle of Theophanes Confessor. Byzantine and Near Eastern History, AD 284-813, Oxford.

MARAVAL, P. (1985), Lieux saints et pelerinages d'Orient. Histoire et géographie. Des origines à la conquête arabe, París. 
MARTIN, ELENA (2006), "Golden Mouths and Speaking Bodies: John Chrysostom's Depiction of Christian Martyrs", Issue 8, pp. 1-20.

MAYER, WENDY (2000), John Chrysostom. The Early Church Fathers, London. --- (2006), The Cult of the Saints: Select Homilies and Letters. Crestwood.

MEEKS, WAYNE A. (1978), Jews and Christians in Antioch in the First Four Centuries of the Common Era, Missoula.

MERGIALI-SAHAS, SOPHIA. (2001), "Byzantine Emperors and Holy Relics. Use, and Misuse of Sanctity and Authority", Jahrbuch der Österreichischen Byzantinistik, 51, pp. 41-60.

NORMAN, A.F. (2000), Antioch as a Centre of Hellenic Culture as Observed by Libanius, Liverpool.

PREGER, TH. (1907), Scriptores Originum Constantinopolitanarum, II, Bibliotheca scriptorum Graecorum et Romanorum Teubneriana.

RETIEF, F.P. \& CILLIERS, LOUISE (2005), "Burial Customs, the Afterlife and the Pollution of Death in Ancient Greece", Acta Theologica Supplementum 7, 44-61.

STEPHENS, W.R.W., 1883, Saint John Chrysostom: His Life and Time, London.

YOUNG, FRANCES M. "Jesus Christ, foundation of Christianity", en Mitchel, Margaret M. (2008), The Cambrige History of Christianity, vol. 1, Cambridge, pp. 1-36.

WHITBY, MICHAEL \& MARY (1989), Chronicon Paschale 284-628 AD, Liverpool University Press

WILKEN, ROBERT L. (1983), John Chrysostom and the Jews: Rhetoric and Reality in the Late 4th Century. The Transformation of the Classical Heritage, Berkeley. 